\title{
Legislação Portuguesa para o Ultramar
}

\author{
Esmeralda Simões Martiner?
}

\begin{abstract}
Resumo: A legislação colonial portuguesa sempre esteve baseada nos princípios constitucionais da "especialidade"; "urgência" e "respeito pelos usos e costumes dos indígenas" consagrados pelo Acto Adicional à Carta Constitucional da Monarquia Portuguesa (1852). Atendendo a estes princípios foram publicadas muitas leis, que nos levam a conclusão de que os princípios constitucionais junto com o princípio colonial universal da "missão colonizadora" justificaram a criação de um regime especial para os indígenas, com a finalidade de tirar-lhes direitos de liberdade e mantê-los como "indígenas", "selvagens", o mesmo que dizer: "excluídos".
\end{abstract}

Palavras chave: legislação - especialidade - indígena - exclusão - colonização

\begin{abstract}
Portuguese colonials overseas laws were based on three fundamental principles: "the speciality", "urgency" and "the respect of indigenous traditions and costums", these principles were estabilished by the "Acto Adicional" to the Cart Constitutional Portugese(1852). Given these principles were published many laws, which regulated the conduct of the african indigens and withdraw their citizenship rigths. We concluded taht these principles along the universal principle of "civilizing misión" justify the creations of a special treatment for indigenous people in order to take their rights of freddom and keep them on as "savages" "natives", the same as "excluded"
\end{abstract}

Key words: legislation - speciality - indigene - exclusión - colonization

\section{1 - LEIS PARA O ULTRAMAR ${ }^{2}$}

As leis que eram feitas para o Ultramar tinham algumas características especiais. Primeiramente, na sua grande maioria, por autorização constitucional, não eram votadas pelo parlamento; secundariamente, eram leis que tinham aplicações exclusivas, e marcadas pelo que se denominou de urgência. Estas características, todavia, só aparecem quando, através do texto constitucional, autoriza-se o Governo a legislar para o Ultramar.

A Constituição Monárquica Portuguesa de 1826 não se referia ao Ultramar explicitamente, isto porque, à altura, o ultramar era considerado como fazendo parte da Nação, art. $2^{\circ}$. Ou seja, a nação era um todo formado pelo reino e seus domínios e a Constituição tinha vigência, sem ressalvas, em todo este território. O que implica que as leis portuguesas eram válidas para as colônias, sem quaisquer alterações.

Entretanto, com a edição do Acto Adicional de 1852, no seu art. 15º, estabeleceu-se a edição de leis especiais para as colônias, começando, oficialmente, a ser observado o regime da autonomia, tão solicitado pelos administradores ultramarinos.

\footnotetext{
${ }^{1}$ Mestre e Doutoranda em História da África pela Faculdade de Letras da Universidade de Lisboa.

${ }^{2} \mathrm{O}$ texto é uma adaptação do primeiro capítulo da dissertação de mestrado da autora - O Trabalho forçado na legislação colonial portuguesa - O Caso de Moçambique (1899-1926) sob a orientação da Profa. Doutora, Isabel Castro Henriques (2008)
} 
$\mathrm{O}$ art. $15^{\circ}$ do Ato mencionado autorizava a edição de leis especiais e sem a apreciação preliminar das Câmaras. Esta última providência, supostamente em função da urgência em que tais leis eram editadas.

Mas que urgência era esta a que se reportava a lei? Como entender a urgência para a edição das leis ultramarinas, quando qualquer lei, seja ela regulando matéria administrativa, tributária, econômico-social, era a qualquer momento editada pelas autoridades competentes?

Que tipo de urgência era essa que permitia que, mudada a direção do Ministério da Marinha e Ultramar, muitas leis fossem publicadas modificando as existentes? Mesmo porque, vale dizer, muitas destas eram promulgadas tão somente como demonstração de poder do novo Ministério. Daí a existência de leis que existiam apenas para contrariar a política anterior ou para satisfação dos novos dirigentes ${ }^{3}$; neste caso, por vezes, voltando a aplicar medidas anteriores que já não tinham dado certo.

O fato é que, a partir da edição do Acto Adicional, as leis ultramarinas começaram a observar princípios diversos dos que eram utilizados para a criação das leis aplicáveis na metrópole.

Os princípios assegurados pelo Acto Adicional eram a especialização e a urgência. Estes se aliavam aos princípios internacionais estabelecidos pela Conferência de Berlim, a saber, a observação dos usos e costumes dos indígenas e o da missão civilizadora, que consistia em elevar o nível moral e material dos indígenas. Tais princípios em seu conjunto nortearam, ao menos teoricamente, a administração colonial, seja quando esta observava o regime de assimilação e o da centralização, seja quando observava a autonomia e a descentralização.

O certo é que ação dos dirigentes, baseada nas observações internas, ou seja; verificadas "in loco" por funcionários ultramarinos, ou ainda influenciadas pelas políticas das outras nações "civilizadoras" - em que se modificavam leis apenas para satisfação do partido que estivesse no comando do Ministério responsável pelo Ultramarfundamentaram a edição das leis que regulavam a vida dos povos do ultramar.

Dentre esses princípios, o da especialidade das leis, parece-nos o que mais abrangência tem. Isto porque engloba, de uma maneira ou de outra, os demais, além de resultar da observância daqueles que viveram e conheceram, ou pensavam conhecer, mais de perto, as dificuldades e problemas que existiam no ultramar. Muitos destes derivados

\footnotetext{
3 Tito de Carvalho, "Revista Ultramarina", Revista Portugueza Colonial e Maritima, Terceiro Anno, 1899-1900, $1^{\circ}$ Semestre, no 25, Lisboa, Ferin,1900 p,49; Manuel Moreira Feio "A Colonisação de Moçambique" I Congresso Colonial Nacional, Vol. I, Conferências Preliminares e Actas, Lisboa, Sociedade de Geografia, 1901, p. 19.
} 
dos diferentes costumes e usos dos diversos povos que povoavam a África portuguesa, que não comportavam soluções provenientes do direito comum.

Se assim não fosse, não se teria colocado a ressalva, no decreto que autorizou a aplicação do Código Civil de 1867 no ultramar, ${ }^{4}$ do respeito aos costumes dos indígenas, art. $8^{\circ}$. Esta é uma prova inequívoca de que a observação dos usos e costumes era uma forma especial, diferente da metrópole, de resolver as questões de acordo com as tradições. Ou seja, uma forma encontrada pela doutrina e apropriada pela administração colonial, para legislar sobre o "Outro".

\section{1 - Especialidade das Leis}

A Especialidade das Leis era uma preocupação constante das autoridades responsáveis pelo Ultramar.

Em princípio, a especialidade para as leis ultramarinas tinha como fundamento, realmente, a suposta diferença entre os povos colonizados e os colonizadores. Argumentava-se que as leis da metrópole não poderiam ser aplicadas a quem estava em tão inferior grau de desenvolvimento. Afinal, estes não teriam capacidade de determinar-se e entender a natureza ou finalidade das leis.

Aos iguais, por pertencerem ao Estado Português, de acordo com o critério do "ius solis", nascidos em território português, como era o caso dos nascidos nas colônias portuguesas, deveriam ser aplicadas as leis comuns. Mas como se justificaria aplicar aos indígenas regras estabelecidas para o convívio social relativas ao direito de propriedade, direito de família, direitos perante o Estado, se estes não conheciam as instituições que fundamentavam toda a proteção do Estado português em relação aos seus cidadãos? Como aplicar aos indígenas as leis protetoras da propriedade privada se os indígenas não a conheciam como tal?

Como aplicar as regras do direito de família, se cada homem poderia ter mais de uma mulher, sem que isto ferisse qualquer principio moral, religioso ou jurídico e se a quantidade de filhos tivesse como finalidade, não só a confirmação da virilidade, como, também, a própria continuidade do poder e da vida? Enquanto os católicos davam valor aos laços de sangue, à família cognatícia, os indígenas eram agnatícios, porquanto a família era constituída por tantos quanto vivessem em comunidade resultante de uma ascendência comum, como também das diversas ligações matrimoniais que se estabeleciam por conveniência e pela manutenção do poder.

\footnotetext{
${ }^{4}$ Decreto de 18 de novembro de 1869.
} 
Era evidente, pois, que a aplicação das leis comuns aos indígenas não teria lógica e, nem tampouco, surtiria qualquer efeito, porquanto para que uma lei seja observada, é necessário que a comunidade para a qual é dirigida aceite-a como uma ordem geral, a que todos devem se submeter em nome de uma paz social. As leis comuns, pois, não serviam para aqueles povos de costumes tão diversos.

Entretanto, a necessidade de normas era premente; afinal o direito tinha de ser positivado, ou seja, escrito para que fosse exigido e observado, tanto pelos aplicadores, quanto por aqueles para quem era dirigido. Assim uma maneira jurídica tinha de ser encontrada para justificar a edição de leis diferentes, para serem aplicadas aos "portugueses" do ultramar.

A necessidade de edição de leis especiais, pois, sempre foi uma constante e a literatura colonial está cheia de exemplos em defesa da observação deste princípio ${ }^{5}$. O tema da especialização das leis relativas ao ultramar fez parte das discussões levadas a efeito no Congresso Colonial Nacional, (1901) realizado em Lisboa, sob os auspícios da Sociedade de Geografia. Nesta, Eduardo da Costa, que fora Governador de Moçambique, se posicionava a favor da autonomia local, "[...] autonomia que não comporta uma suprema liberdade, mas que significa uma grande iniciativa de aç̧ão para dirigir todos os negócios do país, provendo de remédio, por legislação apropriada e local, a todas as necessidades de momento [...]”’. Esta autonomia, implicitamente, significava aderir à especialização das leis reguladoras da vida colonial. Isto porque se o Governador era quem, em princípio, vivendo e convivendo na colônia sabia das suas dificuldades - sobretudo em relação aos costumes dos seus indígenas e a ineficácia das medidas tomadas pela metrópole-, logicamente, deveria ser ele o responsável por tomar medidas adequadas às condições locais. Algo que significa afastar-se do direito comum elaborado pela metrópole e criar, ou sugerir, normas “especiais".

Por vezes, esta especialidade era sugerida como tendo um caráter provisório, como pode-se observar, por exemplo, das palavras do congressista Marnoco e Sousa: "[...] a manutenção dos usos e costumes indígenas deve-se considerar como uma situação provisória [...]"

\footnotetext{
5 V. Sá da Bandeira, O Trabalbo Rural Africano - A Administração Colonial, Lisboa, Imprensa Nacional, 1873, p.118; Antonio Ennes, Moçambique- Relatório apresentado ao Governo, $4^{a}$ ed facsimilada pela de 1946, Lisboa, Imprensa Nacional. 1971, pp.71-72; Joaquim Mousinho de Albuquerque, Moçambique 1896-1898, Lisboa, Sociedade de Geografia de Lisboa, Reimpressão autorizada, 1913, p. 175; Arthur M. Girault. "Condition dés Indigènes au point de vue de la legislation civile et criminelle et de la distribution de la justice", Congrès International de Sociologie Coloniale, Tome Premier, Raports et Procès-Verbaux dês séances, Paris,Arthur Russeau Editeur, 1901,pp:53-54; Thomaz de Almeida Garret, Administração Colonial,1 ${ }^{\circ}$ Vol.ed do autor. sd:pp179180,199; Ruy Ennes Ulrich, Economia Colonial. Liçoes feitas ao Curso do $4^{\circ}$ ano jurídico do ano de 1909-1910, Vol I, Coimbra, Imprensa da Universidade, 1910,p 33; Marcelo Caetano, Portugal e o Direito Colonial Internacional, Lisboa, Livraria Moraes,1948: PP.14, 18-19

${ }^{6}$ Eduardo Costa, "Governos Coloniais" Revista Portuguesa Colonial e Marítima, Quarto Anno, 1900-1901, n ${ }^{\circ}$. 41 e 42, Lisboa, Ferin,1901pp.:258-269,321)
} 
porquanto, segundo ele, os indígenas com o contato com os europeus tenderiam a aceitar e respeitar as instituições européias, assemelhando-se assim aos habitantes da metrópole. Mas achava que, até que isto pudesse acontecer, havia "[...] necessidade de uma legislação especial [...]"” Acrescente-se, entretanto, que dito professor era, contraditoriamente, contrário à assimilação, e dizia, citando Leroy Beaulieu, ${ }^{8}$ que “[...] Os indígenas não querem a nossa legislação e nós também não temos interesse algum em a impor [...]"

O fato é que a idéia reinante à época era que os desiguais não poderiam ser tratados igualmente, porque se a metrópole o fizesse, estar-se-ia afastando-o ainda mais da igualdade. Afinal, os colonizadores eram vistos com incapazes. Ademais, cada uma destas regiões tem as suas particularidades, as suas condições geográficas, os seus costumes e tradições e, portanto, a legislação local tinha que observar tal fato para atender ao bem estar da população. Justificava-se, assim, a especialidade, que vem a ser um regime de aplicação exclusiva dentro dos respectivos espaços, para o qual a lei é criada. A igualdade, entretanto, como veremos, foi distanciada dos seus valores no que se refere ao ultramar.

A especialidade das leis para o ultramar após o Acto Adicional de 1852 passou a fazer parte do texto constitucional, vide que a Constituição da República Portuguesa (1911) no art. $67^{\circ}$ consagra o princípio. Assim como também fez parte do Acto Colonial (1930), constitucionalizado pela Constituição Política da República Portuguesa (1933), art. 25: “[...] As Colônias regem-se por diplomas especiais nos termos deste titulo [...]”.

O Congresso Colonial Nacional de 1901 ocupou-se em diversos momentos da legislação colonial. Muitas das conferências tratavam da especialização da legislação ultramarina, como uma das soluções para o caos administrativo que campeava no ultramar.

J.C. Carvalho Pessoa, ${ }^{9}$ na Conferência realizada em 01 de junho de 1901, faz inúmeras críticas à legislação metropolitana que era aplicada nas colônias. Trazia muitos exemplos do caos que era a aplicação de leis no ultramar. Em especial, o poder desmedido dos governadores e funcionários ultramarinos de editar regulamentos e portarias para regulamentar e, até mesmo, explicar o próprio sentido da lei. ${ }^{10}$

Diz o autor da conferência que "[...] o que está provado é que se não pode promulgar uma lei geral para todas as colónias e que se deve attender às circunstâncias próprias e aos usos e costumes de cada

\footnotetext{
7 Marnoco e Souza, “A Assimilação dos Indígenas e seus Inconvenientes”, Antologia Colonial Portuguesa, Vol. I. Lisboa, Agência Geral das Colónias, 1946, p. 107.

${ }^{8}$ Paul Leroy Beaulieu, De la colonisation chez les peuples modernes, Paris, Félix Alcan Éditeur, Vol II, 6a ed. 1908, p. 100.

9 J.C Carvalho Pessoa, “A Nossa Legislação Ultramarina - Analyse Crítica” Boletim da Sociedade de Geografia $\mathrm{n}^{\circ}$ 16, $19^{a}$ Série, Lisboa,Imprensa Nacional, 1901p.503-519.

10 Idem.p. 508
} 
uma d'ellas para se decretar especialmente o que também para cada uma d'ellas convier [...]". ${ }^{11}$ A África não é igual, portanto, não pode ser homogeneizada para efeito da legislação.

$\mathrm{Na}$ Conferência indicada, o autor reporta-se aos casos de aplicação da lei que deviam ser observadas nas colônias, e até mesmo na metrópole, sem que a especialidade de cada uma delas tivesse sido levada a efeito na elaboração do diploma legal pertinente. Conta-nos ele que foi editada uma lei copiada da legislação francesa, em que apenas foi feita uma tradução da norma. Esta lei referia-se ao fato de que da obrigação do veterinário tomar uma medida prevista no diploma legal, qual seja, seqüestrar da praça pública animais doentes, sendo estes encaminhados para locais adequados, para evitar a contaminação das demais e não causar danos ao público. Na prática, porém, se havia um animal doente, como uma vaca tuberculosa, nos territórios portugueses de Ultramar, não haveria estábulos para levá-los, conforme previa a lei. Portanto, esta não poderia ser cumprida.

Na mesma palestra trouxe à colação muitas outras situações envolvendo a legislação ultramarina e a dificuldade da sua aplicação, exatamente pela falta de observação da peculiaridade de cada colônia.

Aliás, um dos objetivos do Congresso supra referido era o de “[...] estudar, quanto possivel minuciosamente, sob a forma de relatórios práticos, os variadissimos problemas da colonização e da administração ultramarina, taes como: revisão da legislação ultramarina, pondo-a em harmonia com o estado actual e com as condições peculiares de cada colónia [...]"12 Ao fim, restaram aprovados alguns votos, que recomendavam a observação das condições especiais das colônias. ${ }^{13}$

A preocupação com as peculiaridades de cada colônia era uma constante e as revistas que tratavam do ultramar estavam sempre noticiando a necessidade da observação destas especificidades na edição das leis. Tito de Carvalho (em sua coluna "Revista Ultramarina" que era publicada pela Revista Portugueza Colonial e Marítima), mesmo antes da realização do Congresso Colonial Nacional, apontava as dificuldades de se legislar para as colônias "[...] resultantes da diversidade das condições de cada uma d'ellas [...]"14.

Nos artigos desse autor, a questão desta especificidade é sempre retomada. Questionava, também, a urgência com que eram editadas as leis ultramarinas.

A especialidade das leis ultramarinas não era uma exclusiva preocupação portuguesa, todas as nações colonizadoras tinham-na como base na edição das normas para

\footnotetext{
11 Ibid..p. 514

12 A. da Silva Rego.O Ultramar Português no Século XIX(1834-1910) Palestras na Emissora Nacional de 16 de fevereiro a 21 de setembro de 1965),Lisboa, Agência Geral do Ultramar, 2a . ed. 1969,287

${ }^{13}$ Congresso Colonial Nacional, Conferências Preliminares e Actas, Vol I. Votos VI, VII, XVI pp. 227-230.

${ }^{14}$ CARVALHO, Revista Ultramarina, p. 49.
} 
aplicação nas suas respectivas colônias. E não poderia ser diferente, porque a diversidade que se apresentava em cada uma delas necessitava de tratamento desigual, até mesmo para que fossem igualadas. A literatura francesa colonial, por exemplo, que inúmeras vezes serviu de exemplo para as autoridades portuguesas, era favorável a observação dos usos e costumes dos indígenas, e, conseqüentemente, da especialização das leis. ${ }^{15}$

Em Portugal, a questão era aventada em todas as esferas, seja entre doutrinadores, administradores locais, seja pelos Ministros da Marinha, aqueles que efetivamente tinham sobre si a responsabilidade da direção do Ultramar. Isto pode ser observado no relatório apresentado a Câmara dos Deputados em 1899, quando o Ministro Eduardo Villaça dá conta de que é necessária uma modificação nas leis ultramarinas, pois, para ele, não era possível "[...] transportar além dos mares os processos de administração que são aplicáveis á metrópole, nem mesmo submeter a regimen uniforme regiões, por vezes tão distinctas [...]". ${ }^{16}$

A especialidade das colônias devido a causas físicas (geográficas) como culturais (diversidade dos usos e costumes dos indígenas) e predisposição racista sempre foi um norte, pois, em relação às medidas administrativas que iam sendo tomadas pelas autoridades competentes. Em suma, aquelas que, por conhecerem todos os problemas locais podiam, efetivamente, procurar soluções para eles, fossem de caráter administrativo, legislativo ou judicial.

Muitas vezes, entretanto, administradores despreparados e imbuídos de superioridade terminavam por cometer grandes heresias administrativas e jurídicas em nome desta especialidade da legislação ultramarina. Este foi o caso do governador interino de Moçambique, Balthazar Freire Cabral, (1897-1899) que, através de portaria publicada no Boletim Oficial de Moçambique, determinou uma reforma da administração da Justiça na qual alterava a organização judicial e normas processuais, sem que isto estivesse dentro da sua competência ${ }^{17}$.

Tais administradores não sabiam (ou fingiam não saber) que esta especialidade não poderia contrariar a lei maior, no caso a Constituição Portuguesa, os Códigos da metrópole, que vigiam no Ultramar (Cód. Penal, Código Civil, Cód. de Processo Civil). Estes sim, os regulamentos gerais que serviam de base para todas as colônias e, também, para as possíveis adaptações. Atendendo apenas a interesses, muitas vezes pessoais e demonstrativos do poder e prepotência, criavam, através de portarias, normas locais que se

\footnotetext{
${ }^{15}$ Leroy Beallieu, De La colonisation chez les peuples modernes, pp. 621-626.

16 Diário da Camara dos Senhores Deputados no 31, sessão de março de 1899, p.14, doravante será citada como DCSD.

${ }_{17}$ Collecção da Legislação Novissima do Ultramar, 1898, Vol XXVI, Lisboa, Companhia Typographica, 1900, p.43, doravante CLNU.
} 
distinguiam de todas as demais vigentes nas demais colônias. Esta criação de normas locais não seria problema, se não contrariasse as determinações contidas nas demais normas regulamentares a que as portarias deveriam referir-se, ou explicarem, para terem execução. Mas, muitas vezes, este não era o caso. Outras vezes, por descaso, não se cumpriam às determinações estabelecidas na lei, o que tornava inócua a própria determinação legal, como o caso que nos dá conta Albano de Magalhães em relação à nomeação das comissões distritais para procederem à codificação dos usos e costumes, a fim de ter aplicação o art.

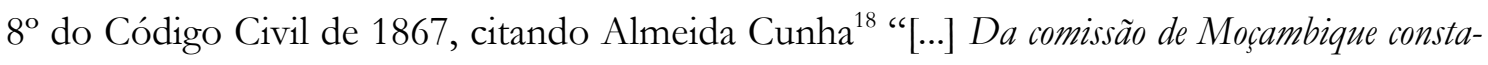
nos, por informação do seu digno presidente, que declara não julgar necessária a codificação dos usos e costumes, por conformarem-se os povos indígenas com as nossas leis [...] "19

O princípio da especialidade das leis ultramarinas foi observado para a edição das leis que regulavam a conduta dos habitantes do ultramar, mesmo nos períodos em que a assimilação tornou-se mais forte, em que circunstâncias locais especiais impediam a aplicação total da legislação comum da metrópole.

Tal base orientadora justificou o regime estabelecido pelo Decreto 12533 de 23 de Outubro de 1926, Estatuto Político, Civil e Criminal dos Indígenas de Angola e Moçambique e tantas outras medidas tomadas pelo Governo. Embora outras causas tenham levado as autoridades a editarem as mais diversas leis que, se algumas vezes assimilavam, outras discriminavam tanto os indígenas que lhes negavam o acesso cidadania. Aliás, o que foi uma constante, pois o pensamento que orientou, durante muito tempo, a política indígena foi o de que o negro pertencia a uma "raça inferior", que não poderia ter direitos iguais aos brancos, aos ocidentais.

$\mathrm{Na}$ exposição de motivos do Decreto 16473 de fevereiro 1929 que alterou o Decreto 12533 de 23 de outubro de 1926, o então Ministro das Colônias, José Bacelar Bibiano, justifica a necessidade do Estatuto Político, Civil e Criminal dos Indigenas de Angola, Moçambique e Guiné, exatamente para respeitar "[...] os usos e costumes, em tudo o que não colida com os direitos individuais de liberdade e de existência, com os princípios de bumanidade e com a soberania de Portugal [...]". Em outro item da exposição ele diz: “[...] Não se atribuem aos indígenas, por falta de significado prático, os direitos relacionados com as nossas instituições constitucionais [...]" ${ }^{20}$

A especialidade das leis para o ultramar tinha a finalidade, em principio, respeitar os costumes indígenas, nativos. Mas existia, também, o que está implícito nas medidas tomadas com base neste princípio, o desejo de negar aos indígenas os direitos decorrentes

18 MAGALHÃES, A. . Legislação Colonial, seu espirito, sua formação e seus defeitos. Estudos Coloniais I, Lisboa, 1907, p 140

${ }^{19}$ Idem.

${ }^{20}$ Diário do Governo. no 30, Ia Série, de 06.02.1929.p. 386-390, doravante D:G. 
da cidadania, legalmente lhes ratificando a inferioridade. Tal era a difusão desta idéia de inferioridade que mesmo um dos grandes defensores e conhecedores dos costumes indígenas, Juiz na Beira e em Timor, Albano de Magalhães, ${ }^{21}$ reconhecia-o abertamente, quando comentava, por exemplo, a extensão de direitos políticos aos indígenas.

Utopias ridículas de quem não investiga, liberalismos piegas de quem nunca perscrutou o abysmo que separa um cérebro de branco do preto, no inicio ainda da sua vida social humana, sem formação de idéias, sem comprehensão, sem reflexão e sem adaptação até às noções sociológicas mais rudimentares! (grifo nosso)

\section{2 - Urgência}

A negação dos direitos de cidadania aos indígenas passava por outra base orientadora para a edição das leis, que era a urgência na sua edição, princípio contido na Constituição.

Se, por um lado, a urgência era necessária em função da demora de apreciação das propostas de leis pelo Parlamento, por outro lado, retirava um dos direitos do cidadão: o de ter as suas regras de conduta votadas pelos seus representantes.

Mas o que poderia ser considerado urgência para a edição de leis ultramarinas? Por que esta urgência foi colocada na Constituição Portuguesa, através do Acto Adicional de 1852. E qual o motivo de estar na lei de 14 de agosto de 1856, que regulava as funções dos governadores?

Por este decreto era considerado urgente: art. $2^{\circ}$. "Todos os casos em que for comprometida a segurança interna ou externa das províncias ultramarinas”.

Qual seria mesmo a questão de segurança interna ou externa que justificava a edição dos diversos "Regulamentos do trabalho indígena", ou a regulamentação de quem poderia ser considerado assimilado, ou ainda, a conceituação jurídica do indígena? A questão era efetivamente política, e por sê-lo, deveria passar por aqueles que eram os representantes da população, para que estes, cumprindo o seu mister, aprovassem o melhor caminho para alcançar os objetivos políticos.

Entretanto, assim não era, porque os representantes do povo não se preocupavam com àquele povo que não era civilizado, tanto que, em 1873, Sá da Bandeira argumentava que a política constitucional, ou seja, aquela pela qual as leis deveriam ser discutidas e votadas no parlamento, não era cumprida em relação ao Ultramar. Isto porque, nas

${ }^{21}$ MAGALHAES, Legislação Colonial, Seu espirito, sua formação e seu defeitos .p 230. 
discussões legislativas "[...] se dá preferência aos negócios que dizem respeito ao continente do reino: do que se segue, haver falta de tempo necessário para se tratarem aquelles que são relativos ao ultramar". ${ }^{22}$

Todavia, o problema da urgência das leis tem muitas outras conseqüências. O Acto Adicional de 1852 determinava que, qualquer lei editada em regime de urgência para o ultramar, deveria ser submetida às Cortes quando estas se reunissem. Ora, esta obrigação de submeter as medidas às cortes tinha que finalidade? Validar a lei? Aprovar a medida? Rejeitá-la? Se a lei não fosse apreciada o que acontecia com os atos praticados sob a sua orientação? São perguntas que muitas vezes ficaram sem respostas e que foram objeto de questionamentos pela imprensa especializada em ultramar. Este tipo de questão foi mais de uma vez levantada por Tito de Carvalho, na sua coluna "Revista Ultramarina", quando analisa um projeto de modificação da carta em relação à apreciação, pelas Cortes, das medidas tomadas pelo Governo com base na urgência.

No projeto fixava-se prazo de 1 ano para que as Cortes apreciassem as medidas, e o colunista questionava, exatamente, qual seria a conseqüência para os atos praticados com base em leis não apreciadas dentro destes prazos? Se a medida fosse rejeitada, o que aconteceria com o negócio realizado com base nela? As preocupações demonstram que a urgência era de grande importância para a edição das leis para as colônias e que sempre foi objeto de questionamentos, análises, estudos e de controvérsias entre as Cortes e o Governo. Sobretudo, as primeiras entendiam que o fato do governo legislar, sem a participação do Parlamento, era uma usurpação de poder.

A urgência institucionalizou, em relação ao ultramar, o Decreto com força de lei: o Decreto ditatorial. O Srs. Ministros da Marinha e Ultramar, depois Ministros da Marinha e das Colônias, adiante Ministros das Colônias, tinham autorização constitucional para legislar sobre os assuntos das Colônias, atribuição que, no nível local, e dentro dos limites estabelecidos pela lei, também era peculiar aos governadores coloniais, ${ }^{23}$ o que se denomina de competência concorrente, embora com limites. Quando se diz competência concorrente nos reportamos ao fato de que os dois níveis de governo, no caso o Ministro (Estado) e os Governadores (Colônias) podiam legislar sobre o mesmo assunto, o que não aconteceria em caso de ser a competência exclusiva de uma das duas esferas.

Em qualquer das hipóteses, seja a lei urgente editada pelo Ministro, seja pelo Governador da Colônia, deveria ser observada a limitação imposta pela Constituição. Esta dizia que o Ministro deveria ouvir, previamente, a Junta Consultiva do Ultramar, e os

22 Sá daBandeira, O Trabalho Rural Africano p.121

23 Art. 15 Parágrafo $2^{\circ}$. do Acto Adicional de 1852 
governadores os respectivos Conselhos de Governo. Entretanto, em ambos os casos, as medidas teriam de ser submetidas ao Parlamento quando este voltasse a funcionar.

Com a extinção da Junta Consultiva do Ultramar em 1911 à altura já denominada Junta Consultiva das Colônias, a função passou a ser exercida pelo Conselho Colonial criado em 27 de maio de 1911 e, a partir de 1926, pelo Conselho Superior das Colônias.

Entende-se, perfeitamente a urgência. Sem dúvida, o Governo não poderia ficar atrelado à boa vontade do parlamento para apreciar as propostas de lei. Afinal, realmente, havia casos de urgência que tinham de ser decididos com rapidez, e só poderiam sê-lo através de uma autorização contida em um diploma legal, que validasse o ato praticado e desse competência a quem o praticasse. Se as autoridades ultramarinas ficassem a espera da apreciação da proposta pelo parlamento, quando esta fosse aprovada já seria inócua, porque a situação para a qual fora criada ou idealizada já mudara, prescindindo de uma nova regulamentação; vide o caso do Senado que, em 1914, ainda estava a discutir o Regulamento do Trabalho Indígena de 1911, que havia sido modificado, exatamente, naquele ano.

Também não se pode olvidar da questão partidária e das próprias inimizades pessoais entre os membros do parlamento entre si, e entre esses e o Executivo. O caso do tratado de Lourenço Marques pode ser um bom exemplo disto.

O fato, entretanto, é que a urgência virou, em relação às leis ultramarinas, uma constante e, em nome dela, "[...] declara-se á pressa a urgência para antes das câmaras reunirem-se se tomarem medidas que lá seriam discutidas ou retardadas, e espera-se que as câmaras fechem para se declarar urgente determinada providencia, [...]". ${ }^{24}$

A proposta de Lei para regulamentar o trabalho indígena nas colônias, que foi precedida de estudos de uma comissão chefiada por Antonio Ennes, foi apresentada à Câmara dos Srs. Deputados, pelo então Ministro da Marinha e Ultramar, em março de 1899. Esta proposta de lei, e mais 12 outras, acompanhavam o relatório do Ministro. Observe-se que todas as treze medidas eram propostas de lei e que eram apresentadas à Câmara para apreciação, antes de sua aplicação na colônia. O que sucedeu, entretanto, é que a Câmara entrou em seu recesso sem que a proposta de Lei regulamentando o trabalho indígena fosse apreciada. Isto levou a que o Ministro, através de Decreto com força de lei, baseado no art. 15 do Acto Adicional, publicasse o regulamento em outubro de 1899, cinco meses após a sua apresentação na Câmara dos Deputados. ${ }^{25}$

\footnotetext{
${ }^{24}$ Albano Magalhães, Legislação Colonial, Seu espirito, sua formação e seus defeitos. p 93.
}

${ }^{25}$ DCSD no. 31 de 23.03.1899, p.84 
Ressalte-se, por oportuno, que tal regulamento teve vigência até o ano de 1911, quando foi revogado, embora praticamente ratificado, pelo Governo Provisório da República Portuguesa, não se tendo notícia de que a Câmara dos Deputados o tenha apreciado.

Apesar de a urgência ser objeto de muitas discussões, porque ela era a causa do que alguns chamavam de usurpação da competência do poder legislativo, foi um meio encontrado para a resolução dos problemas ultramarinos, que não permitiam a espera pela decisão do legislativo; e como princípio legal que era, constitucionalmente assegurado, serviu de base e fundamento para a edição de leis ultramarinas ao longo do tempo.

Entretanto, o princípio que era utilizado, quase sem restrições, na metrópole, não resolvia, na prática, a problemática da regulamentação das diversas situações coloniais. Isto porque esta por sua própria dinâmica e mutações freqüentes, necessitava que as medidas administrativas, e não só estas, fossem mais rapidamente aplicadas e/ou modificadas.

Observemos bem toda a burocracia para que uma lei entrasse em vigor e tivesse a sua aplicação nas colônias. Primeiramente, o Ministro teria de, por força do estabelecido no art. 15 do Acto Adicional de 1852 e na legislação que lhe foi posterior, ouvir os órgãos consultivos - Junta Consultiva do Ultramar, Conselho do Ultramar, Conselho das Colônias, nos seus respectivos períodos de existência; sendo que algumas vezes, como no caso do Regulamento do Trabalho dos Indígenas (1899), a consulta era precedida por estudos de alguma comissão nomeada para este fim. Posteriormente, se as Cortes não estivessem em recesso, teria de apresentar o projeto de lei para deliberação, ou então, valendo-se do artifício legal permitido constitucionalmente, declarar a urgência da medida e editar a lei. Após isto, cada colônia deveria publicar o diploma legal em seus respectivos "Boletins Oficiais”. Publicada a medida, muitas vezes era necessária a publicação de portaria local explicativa, ou então, em casos de reformas administrativas, mui particularmente as que determinavam a criação de cargos, aumentos de despesas e outras medidas, tinha-se que aguardar que a despesa fosse autorizada ou, ainda, a chegada do funcionário que ocuparia o cargo ou a função criada, existindo, também, os casos em que a medida precisava de ser regulamentada pelo Governador para adaptação às condições locais. Todo este processo burocrático demorava tanto que, não poucas vezes, a própria lei era substituída por outra, sem que houvesse o cumprimento da anterior. Assim, a questão da urgência tinha, em si, uma contradição. Servia, na metrópole, para que os srs. Ministros tomassem as medidas que acreditavam urgentes, de acordo com as suas convicções e orientação partidária, sem a 
interferência do legislativo, mas não proviam o ultramar, com a urgência que deveria, dos meios para a aplicação da medida tomada.

Podemos concluir, pois, que a declaração de urgência não era, de nenhuma maneira, em todos os casos em que foi utilizada, uma questão de necessidade inadiável, e sim um meio técnico-legal, constitucionalmente assegurado, de legislar para o ultramar sem a participação do parlamento. Todavia, não era garantia de aplicação e observação da lei.

O princípio da urgência foi incluído em todos os textos constitucionais a partir do Acto Adicional de 1852. No Acto Colonial (1930) foi admitido com os limites estabelecidos no Parágrafo Único do art.27. e, ao longo de todo o período abrangido por este estudo, serviu, praticamente, como base legal para a grande maioria das leis editadas, ditatorialmente, pelo Executivo para o Ultramar.

\section{3 - Respeito aos usos e costumes indígenas.}

Tudo o que se disse a respeito da especialidade, e por isso foi dito que de todos os princípios ele é o mais abrangente, porque engloba todos os demais, vale em relação à aplicação do princípio que titula este item.

A questão é lógica. Se era preciso civilizar quem é diferente de mim, tenho que chegar até ele, conhecer os seus hábitos, a sua cultura, as suas instituições e particularidades. É uma lei "normal" da alteridade. O outro precisa ser identificado e conhecido para que com ele se possa interagir. E, no caso de Portugal, poder dominar.

Nesta lógica, não é escusado dizer que a geografia, entendendo-se como tal o espaço físico e suas características, tem uma participação importantíssima para variação destes hábitos tradicionais dos povos. É ela que condiciona o tipo de atividade lucrativa, a maneira de desenvolver esta atividade, as condições climáticas, a facilidade ou não de locomoção e comunicação dos povos, a maneira de vestir, de alimentar-se.

O esforço de todas as nações colonizadoras em criar e fomentar as atividades das Sociedades de Geografia não foi vão, exatamente pelo fato de que estas sociedades, com os seus estudos e expedições, em muito contribuíram para o conhecimento das terras e dos costumes e usos dos seus habitantes nas respectivas colônias.

Não só a geografia, mas outras disciplinas que, conjuntamente com esta nos trazem o "Outro" com uma maior probabilidade de conhecimento e de interação, foram utilizadas no trato com os indígenas e com o seu habitat.

Se as nações colonizadoras tinham como finalidade explorar as colônias ou povoálas, em qualquer dos casos, o trato com os indígenas era fundamental. Era preciso conhecer 
os seus hábitos, a língua, as suas instituições. Estamos na ordem do discurso, no conhecer; não chegamos ainda no respeitar, o que se afigurava, de uma maneira geral, aos olhos ocidentais, uma heresia, isto no caso que estamos a analisar. Como seria possível aos brancos, de uma civilização considerada por eles tão superior, respeitar hábitos de "bárbaros" "selvagens"?

O problema é que, gostando ou não, entendendo ou não, para que as nações colonizadoras se estabelecessem, o respeito aos usos e costumes dos naturais da terra tinha de ser observado para que o mínimo de organização fosse alcançado, porquanto era necessária a colaboração dos naturais da terra para que os objetivos dos colonizadores, seja de povoação, seja de exploração das colônias, fossem atingidos. No caso de Portugal, mais ainda, tendo em vista que a população portuguesa e a pobreza do país não permitiam o estabelecimento de uma quantidade substancial de colonos portugueses nas colônias, para fazer frente ao contingente africano.

Os indígenas tinham as suas instituições $\mathrm{e}$ as suas crenças. $\mathrm{O}$ direito consuetudinário existia com toda a força entre eles, e uma ordem jurídica baseada em costume, na oralidade, não se muda apenas com a edição da lei escrita. Afinal, se esta não fosse aceite por aqueles aos quais se dirige, termina por ser letra morta, perdurando a tradição.

No caso dos indígenas portugueses então, a questão era mais problemática, porque estes não sabiam a língua do colonizador, que por sua vez também não sabia a deles. A dificuldade da comunicação era enorme, e, ademais, aquelas pessoas de hábitos tão diversos estavam entrando nos seus domínios, apropriando-se das suas riquezas, devastando suas populações, destruindo seus lugares sagrados, impondo-lhes uma religião, afastando-lhes das suas famílias, das suas tradições, das suas crenças, utilizando as suas forças, o que gerava o medo e, consequentemente, uma reação hostil.

Este medo ${ }^{26}$ também alcançava o colonizador, embora este não pudesse existir ou ser demonstrado. Afinal, a grande maioria dos que estavam na administração das colônias eram militares que foram adestrados para nada temer - como se o medo não fizesse parte do próprio ser humano e do seu natural desejo de sobrevivência. O medo do colonizador era daquele ser desconhecido para eles, daquelas figuras tão diferentes do que se entendia por um "ser humano pertencente à raça branca". Seu padrão estético do que era o belo, o

26 Hanna Arendt, As Origens do Totalitarismo, Imperialismo e Expansão do Poder, uma análise dialética RJ. Editora Documentário,1976. p.100-101(tradução de Roberto Raposo) 
sábio, o que era capaz de aprender, e, mais importante, o que era capaz de ensinar e, de com o seu exemplo, civilizar. ${ }^{27}$

Hannah Arendt reportando-se ao imperialismo colonial, afirma que este se serviu de dois mecanismos de domínio e organização política dos povos descobertos; a raça e a burocracia: "[...] a raşa como principio da estrutura política; o outro, a burocracia como principio do dominio no exterior". A raça, "[...] foi uma forma de explicar a existência de seres bumanos que ficavam à margem da compreensão dos europeus, e cujas formas e feições de tal forma assustavam e humilhavam os homens brancos, imigrantes e conquistadores, que eles não desejavam mais pertencer à mesma comum espécie bumana"28.

A autora não poderia ser mais objetiva e clara; o "Outro", o indígena era um fator negativo e o branco em nada poderia se igualar a ele. Era preciso dominá-los, devorá-los, como se refere Castro Henriques, ${ }^{29}$ fazer com que eles entendessem, perfeitamente, a sua inferioridade. Era preciso afastar o terror de ser um dia comparado com "aquilo", que Oliveira Martins ${ }^{30}$ classificava de "[...] não raro próximo do antropóide e bem pouco digno do nome de homem".

É interessante notar, entretanto, que a constante inferiorização do negro, se olhada de outro ângulo, diferente do que nos é apresentado pela literatura colonialista e documentos produzidos pelo colonizador, possibilita um entendimento de que a inferioridade, em relação à África, era exatamente dos colonizadores, não só pela sua quantidade numérica, mas pelo próprio desconhecimento de todos os hábitos, línguas, meios de cura de doenças, geografia física. Enfim, do que eram aquelas terras, aquelas águas, aquele mundo desconhecido para o Ocidente, que se imperializava e precisava de expandir os seus mercados e encontrar locais onde pudessem obter as matérias primas que lhes eram necessárias, bem como mão- de- obra barata.

Se o colonizador precisava locomover-se em África, precisava de braços para carregar os seus apetrechos, necessitando, pois, dos “indígenas!"; se necessitava de um guia que conhecesse bem uma região, dependia do "indígena"; se precisava lutar contra um determinado chefe indígena, tinha de aliar-se a outro chefe que com aquele tivesse diferenças; se precisava plantar, precisava de braços "indígenas"; portanto, a inferioridade em muitos aspectos, não foi do "Outro", e sim do "Mesmo" que a nada disto estava

\footnotetext{
${ }^{27}$ V. Isabel Castro Henriques. Os Pilares da Diferença- Relações Portugal-África Séculos XV-XX, Caleidoscópio, 2004,p.51

${ }^{28}$ Hanna Arendt, As Origens do Totalitarismo, Imperialismo e Expansão do Poder, p 93.

${ }^{29}$ Castro Henriques, Os Pilares da Diferença, p.42

${ }^{30}$ Joaquim Pedro de Oliveira Martins. O Brasil e as Colónias Portuguesas, Lisboa, Guimarães editores, 1953, p. 255
} 
acostumado, e os que estavam, quando chegavam em África, por se julgarem superiores, não queriam fazer aquele trabalho indigno e que o igualaria àquele. $O$ certo é que nada sabiam da vida e dos costumes, para si bárbaros, mas que eram a história viva daqueles que, devido a uma organização tribal, hierarquizada, institucionalizada, ${ }^{31}$ souberam manter as suas tradições e não permitir que aquele outro, que lhas queriam acabar, o fizessem. Os termos de vassalagem firmados com os chefes das várias tribos indígenas são exemplos da necessidade dos portugueses de manterem com os naturais da terra uma relação amistosa e necessária, porque estas avenças permitiam a própria defesa dos territórios, em relação aos demais colonizadores, dentre outras vantagens. Para os chefes indígenas, a aliança garantia os seus poderes em relação às outras tribos indígenas, e em relação ao próprio colonizador, que reconhecia, desta maneira, o próprio poder do chefe local. Há nestes acordos uma troca visível de favores, embora os portugueses tivessem maiores vantagens, porque utilizam o poder dos chefes indígenas para os seus propósitos, como o fato de torná-los arrecadadores dos impostos, fornecedores de mão-de-obra, e quando necessário, defensores dos territórios.

A rendição dos portugueses aos usos e costumes indígenas foi, pois, imprescindível, tecnicamente pensada e correta, sem que isto acontecesse, o que conseguiram sem que a força estivesse presente, não teria sido alcançado. Quando falamos em rendição, evidentemente, estamos nos reportando ao fato de que os colonizadores tiveram de tolerar alguns dos usos e costumes dos indígenas, como forma de chegar até eles, e não só para isto, como também, em linguagem atual, para que tudo isto servisse de marcadores culturais, que mantivessem a própria diferença que sempre existiu, mesmo nos momentos em que se falava em assimilação, quando todos eram considerados "portugueses" porque nascidos no território português e sujeitos as mesmas leis. O critério da representação do ultramar no parlamento é uma boa maneira de testar o tratamento desigual que era dado ao ultramar e aos indígenas, no particular.

O maior problema de levar a efeito o respeito a estes usos e costumes estava em que eles eram desconhecidos e, necessariamente, para ter aplicação, tinham que ser conhecidos, o que para a época significava: codificados. A codificação em questão foi muitas vezes determinada, no entanto, poucas vezes, ou quase nenhuma, atendida, devendo-se atribuir isto, exatamente, à diversidade existente entre os inúmeros povos que habitavam as colônias, além da desídia (negligência) dos funcionários a quem incumbia este estudo e codificação. Em uma só colônia, a exemplo de Moçambique, pelo determinado no

\footnotetext{
${ }^{31}$ Agostinho Coelho, Relatório do Governador da Provincia de Moçambique, 1883.p. 332.
} 
Código Civil de 1867 e decreto de 18 de novembro de 1869, que tornou a sua aplicação obrigatória no ultramar, deveriam ser respeitados os usos e costumes dos baneanes, bathiás, parses, mouros, gentios e indígenas ${ }^{32}$. O que significava a codificação de todos, lembrando que no caso específico dos indígenas, muitas outras teriam de ser observadas.

As Comissões criadas para elaborarem estes projetos de codificação não tiveram êxito e a determinação desta codificação, muitas vezes repetidas, não teve efeito.

Observe-se que a determinação para a codificação foi estabelecida em 1869. Mas se tem notícia do Código de Milandos Inhambanenses só foi aprovado por Portaria Provincial em 1889. O que é da urgência? Se foram necessários 20 anos para que uma codificação, que fora resultado de uma determinação legal, fosse aprovada! Isto vem a ratificar exatamente o que se disse a respeito da urgência, que era mesmo uma formula técnico-legal encontrada para que as leis do ultramar fossem editadas sem passar pelo parlamento; e que os usos e costumes, mesmo não codificados, foram observados, pelo menos a nível local, pelos administradores, mui principalmente, no que se refere às questões judiciais.

Entretanto, a questão da codificação dos usos e costumes era um pensamento utópico, e que não resultaria para os efeitos desejados. O fato de "positivar" o direito consuetudinário significaria a sua provável extinção, retirando-se dele o seu dinamismo.

\section{4 - Missão Civilizadora}

A "missão civilizadora" consiste, para a grande maioria das nações colonizadoras, mais acentuadamente, após a Conferência de Berlim, o dever de zelar pelo bem estar das populações indígenas, de trazê-los à "civilização", e de melhorar as condições morais, materiais e jurídicas destas populações.

Pela sua importância fundamental, e por ser um princípio internacional que foi observado pelo conjunto formado pelas potências colonizadoras, falamos primeiro dos peculiares a Portugal, daqueles criados pela legislação interna do país exatamente para dar sustentáculo ao maior deles: o da missão civilizacional. A partir deste passamos a tratar, mui particularmente, de sua íntima ligação com o mundo do trabalho indígena, que faz parte do nosso objeto de estudo.

Essa missão civilizadora tinha duas espécies de objetivos: os explícitos e os implícitos. Dentre os explícitos, internacionalmente acatados pelas potências colonizadoras, estão os que tinham a finalidade de melhorar as condições materiais e morais dos indígenas, uma ideologia comum aos "civilizadores". Nos implícitos podemos identificar aqueles que

\footnotetext{
${ }^{32}$ CLNU, 1868-1869, p.335.
} 
se referem a uma melhoria, mas não da vida dos indígenas, e sim das nações colonizadoras, que precisavam de novos mercados e de matérias primas, além de um lugar onde pudessem colocar os seus excedentes populacionais, e muitas das vezes, como aconteceu em Portugal, a sua população carcerária. Neste particular o exemplo fica com Angola, para onde foram enviados muitos que tiveram de cumprir a pena de degredo.

O que nos interessa são os motivos explícitos da missão civilizacional, porque neles se concentraram os colonizadores, vez que tinham de encontrar os meios adequados e legais para o exercício desse mister. Por outro lado, eles revelam a existência dos motivos reais aí implicados, embora em muitas oportunidades, ocultados, implícitos; o que esperamos demonstrar com a análise da legislação.

A idéia de missão civilizadora se legitimava como um projeto que pretendia melhorar as condições materiais dos indígenas. Algo que, para os olhos dos ocidentais, estava ligado a satisfação de necessidades conforme o próprio modelo ocidental, e não aquelas originadas do "modus vivendi" dos nativos, dos seus hábitos que levavam, ao seu critério, a uma vida saudável, confortável e digna, adaptada ao momento civilizacional em que viviam.

Para os indígenas, as necessidades eram completamente diversas das dos ocidentais, sendo satisfeitas com a sua própria produção e com as suas trocas. Os indígenas tinham a sua agricultura de subsistência, tinham a sua artesania, sabiam trabalhar com minerais e tinham uma rudimentar indústria de transformação.

O que seria melhorar as condições materiais para os ocidentais? Ensinar aos indígenas técnicas agrícolas modernas para uma produção em grande escala, que a eles em nada beneficiava? Mostrar aos indígenas que além das bebidas espirituosas que eles conheciam e fabricavam a partir dos seus frutos e raízes naturais, existiam outras que tinham o mesmo resultado, ou seja, lhes deixariam alcoolizados, enriquecendo os produtores de vinho da metrópole? Fazer com que os indígenas fossem obrigados a cultivar o algodão, para depois que este fosse industrializado na metrópole, retornasse para a colônia em forma de panos e fatos para que o indígena os comprassem e se caricaturassem? Fazer com que os indígenas tivessem as suas palhotas para lhes cobrar o imposto que serviria aos cofres do Estado?

Se bem observarmos o que se queria alcançar, ou seja, o objetivo implícito que se queria obter com a melhoria das condições materiais e morais dos indígenas, temos que, na grande maioria das situações, o resultado favorecia, realmente, ao colonizador. 
Retoma-se a questão agrícola, como exemplo. Quando se melhora a técnica e a produção agrícola aumenta, quem se beneficiava era o dono da plantação, que não era indígena. Este só tinha direito a uma participação nesta produção. Ou, quando aproveitava algo desta, em alguns casos, quando se fazia o encontro de contas, o indígena estava sempre em débito para com o seu "partner”. O caso das pontas na Guiné portuguesa é um bom exemplo disto. Ali, as pontas eram terrenos demarcados por um comerciante que fornecia a quem quisesse ali trabalhar, as sementes e, até mesmo, o próprio sustento durante a cultura, com a obrigação de que, no final da colheita, lhe fosse pago 100\%, ou mais, deste adiantamento. Era uma espécie de "parceria", mas sempre havia prejuízo para um dos parceiros. ${ }^{33}$

Da mesma forma, quando eram introduzidos hábitos alimentares novos para os indígenas, é certo que havia aumento o consumo dos gêneros alimentícios. Mas o mais favorecido era o fornecedor de tais gêneros e não, diretamente, o indígena, que simplesmente acresceu mais um item às suas necessidades. Isto porque quando se colocava um novo produto no mercado, produto este do qual se detinha o monopólio, e se obrigava os indígenas ao consumo, eliminando a concorrência nativa (fabricação das bebidas pelos indígenas), se acrescia mais uma necessidade à vida dos indígenas, o que funciona duplamente em negativo para si, que passava a gastar mais com a bebida e mantinha-se dependente do alcoolismo.

No que se refere à elevação moral dos indígenas, aqui também há objetivos explícitos e implícitos. Os explícitos são aqueles delineados pelas questões altruísticas e humanitárias. Os implícitos, fazer com que os indígenas aceitassem com maior facilidade os hábitos dos brancos, a fim de que o convívio e a comunicação entre estes e os primeiros fosse o mais amigável possível, o mais pacifico para que a submissão fosse ainda maior.

A melhoria das condições morais dos indígenas tinha a finalidade de incutir neles hábitos e crenças que afastassem os traços da sua vida tradicional, distanciando-os dos seus usos e costumes. Afinal, estes eram considerados bárbaros, e era preciso fazer os indígenas aceitarem o "mundo correto" dos ocidentais. Neste aspecto as coisas tivessem de andar vagarosamente, porque os usos e costumes de um povo não são passíveis de transformações apenas com exigências legais, com novas leis, e nem com intenções altruísticas; e, quanto a isto, os colonizadores tiveram, efetivamente, de recapitular.

No que concerne ainda à melhoria das condições morais dos indígenas, temos que um elemento de grande importância e, até mesmo fundamental, para os fins da missão

${ }^{33}$ Frederico Silveira, "Guiné" Nova História da Expansão Portuguesa - O Império Africano 1825-1890, Vol. X Jill Dias e Valentim Alexandre (coord), Lisboa, Estampa, 2001. p. 254. 
colonizadora, foi o religioso. Ser civilizado era ser católico, crer em um Deus justo e onipotente, que assegurava a diferença entre colonizador e colonizado; que teria dado aos primeiros a missão de trazer os segundos para a sua glória, com a divulgação e expansão da sua $\mathrm{fe}^{34}$. Em Portugal e suas colônias o elemento religioso teve papel primordial. Os religiosos, fiéis aliados do Estado português mesmo quando já não eram subvencionados por este, eram os responsáveis pela pregação do evangelho e pela educação dos indígenas, o que significava o ensinamento da língua portuguesa e das qualidades morais que o homem deve ter para receber tal qualificação. Dentre elas, a obrigação de trabalhar e de sustentar-se, através deste esforço, reconhecido e louvado por Deus, a si e a sua família, família nos termos concebidos pelos ocidentais: pai, mãe e filhos havidos de uma união matrimonial abençoada por Deus. Neste particular, falharam o Estado e a religião dos colonizadores. Em primeiro lugar, porque tiveram de aceitar o matrimônio da maneira como ele era realizado na África portuguesa, na qual os homens podiam ter diversas mulheres. Isto se realizava explicitamente, sem maiores subterfúgios como era peculiar aos povos civilizados que tinham e mantinham outras mulheres, que não a própria esposa, as “teúdas e manteúdas". Secundariamente, na própria religiosidade em si, que não alcançou o objetivo de afastar as religiões tradicionais dos indígenas, nem tampouco o islamismo, como se desejava.

Em relação aos métodos utilizados pelos colonizadores para melhoria das condições morais dos indígenas, temos que, em muitos casos, a estratégia utilizada pelos portugueses foi uma tolerância seletiva. Toleravam-se alguns hábitos, todavia impunham-se muitos outros, sendo esses outros os que eram materialmente proveitosos aos portugueses. Um terceiro fator soma-se aos anteriores. Além de educar e ensinar a língua deveria ser dada uma qualificação jurídica aos indígenas, a fim de que direitos e deveres pudessem ser assegurados e exigidos. Este era o objetivo explícito. O implícito era saber como retirar aos indígenas os seus direitos à propriedade do solo, à sua liberdade de ir e vir, a sua liberdade de ter os seus "deuses", de contratar os seus serviços, e lhes impor o dever de trabalhar, de pagar impostos, sem que nada disto fosse considerado ilegal.

Como então se fazer isto? Como retirar dos indígenas os direitos de cidadãos, que, especificamente no caso português, lhes era atribuído até o momento em que ficou estabelecido, em lei, que eles deveriam ser regidos por leis especiais?

Exatamente através destas leis especiais, que serviam para demonstrar todos os objetivos implícitos da colonização. Era o momento de transcender do discurso

34 Marcelo Caetano, Tradições, Princípios e Métodos da Colonização Portuguesa, Lisboa, Ag. Geral do Ultramar,. 1951, pp 32, 42-43. 
colonizador para a ação prática. Era a hora de retirar dos indígenas a sua liberdade e de submetê-los à autoridade portuguesa, que lhes dirigiria a vida, determinando o que eles podiam ou não fazer, como andar, como se vestir, para quem trabalhar, o que beber, e onde gastar. O Estado Português chegou mesmo a constitucionalizar os fins explícitos da colonização no art. $2^{\circ}$ do Acto Colonial, que passou a fazer parte da Constituição Portuguesa em 1933:

\begin{abstract}
É da essência orgânica da Nação Portuguesa desempenhar a função histórica de possuir e colonizar domínios ultramarinos e de civilizar as populações indígenas que neles se compreendem, exercendo também a influência moral que lhe é adstrita pelo Padroado do Oriente. ${ }^{35}$
\end{abstract}

A prática concretizava o objetivo implícito: rebaixar o "status quo" do indígena. Fazê-lo efetivamente um indígena. Retirar-lhe qualquer status de cidadão português, que já lhe fora afastado tantas vezes e em diversos momentos: na autorização constitucional para ser regulado diferentemente dos portugueses. Através das leis especiais: nas leis de assimilação; na exigência de pedir autorização para mudar de residência; na exclusão do direito de voto; na exigência de comprovar a condição de assimilado; no regime de concessão de terrenos.

O certo é que a idéia de civilizar estava intimamente ligada à inferiorização dos indígenas africanos. Somente acentuando esta inferioridade do "Outro", o "Mesmo" poderia mais facilmente dominar. Os verbos empregados no discurso civilizador não deixam a menor dúvida disto: colonizar, assimilar, ensinar, melhorar, proteger, obrigar; mas estes mesmos verbos podem mostrar outra faceta da colonização, que não faz parte do discurso oficial. Colonizar, em se tratando da África portuguesa, significa constatar a existência de um povo com história, com cultura, que passou a fazer parte da própria história portuguesa, que, insistentemente, tentava negativá-la, como forma de confirmar a sua própria. Ou seja, a história oficial dos grandes descobrimentos e do pioneirismo da própria missão civilizadora, que encontrando "selvagens" busca transformá-los através do evangelho, em novos cristãos, cumprindo a missão secular de Portugal na terra, que lhe teria sido confiada por Deus.

A preocupação era retirar a história do "Outro", e fazê-lo aceitar a do "Mesmo", criando arremedos de europeus. Por isto mesmo, objetos da ironia, do sarcasmo, patrocinado pelo racismo velado, mas identificado dos portugueses. $\mathrm{O}$ que, aliás, perdura hoje em dia e é facilmente visível, quando observamos os olhares, dos de pele clara, que são lançados aos de pele escura, que insistem em povoar o Rossio e adjacências.

\footnotetext{
35 Coletânea da Legislação Colonial, Lisboa, Ag. Geral das Colónias, 1936, p. 49.
} 
O assimilar é também uma forma de negação, porque transmite a idéia de que o que o "Outro" tem não presta, está fora do padrão. Sendo assim, para que ele possa crescer, no caso dos indígenas, dever-se-ia "civilizar". É preciso assimilar os costumes dos que se julgam superiores, evidenciando, assim, toda a carga de racismo que marcou todo o processo colonial. Isto foi muito bem caracterizado por um vogal do Conselho de Governo de Moçambique quando, na discussão de uma proposta de aumento do funcionalismo que foi proposto pelo Procurador da Coroa e Fazenda, em relação à equiparação dos vencimentos dos amanuenses, Eduardo Saldanha, representante da Associação dos Proprietários, opinava por uma classificação, agrupando-os em $1^{\mathrm{a}}$ e $2^{\mathrm{a}}$ classe. À primeira pertenceriam os europeus e à segunda, logicamente, aos indivíduos de cor que teriam vencimentos menores. Entretanto, pior de que a proposta da divisão é o posicionamento do Sr. Agnelo Ferreira que, sarcasticamente, diz " [...] que gosta muito da cor, mas para fundo de quadro. Só a admitte para fažer realçar a raça branca[...]"36

Por ensinar, neste sentido, entendia-se a transmissão do que era aceite como correto no plano europeu, sem levar em consideração o saber do "Outro" que, para os "sábios", nada tinha a ensinar. Esta era mais uma forma de negativar o indígena, até porque, segundo uma grande parte dos administradores, baseados em argumentos "científicos", os indígenas não tinham capacidade mental para aprender, e, se não tinham esta capacidade, também não poderiam ensinar nada, porque de nada sabiam. Lembremosnos que o colonizador exercia uma tutela sobre os indígenas, e quem é tutelado, em bom direito, é incapaz.

Os verbos outros que dominam o discurso, também têm toda uma carga negativista, mas um deles demonstra todo o "poder" que se pretendeu ter sobre os destinos dos indígenas africanos. Era o direito dos colonizadores de "obrigar o indígena ao trabalho". Com isto, estes deixaram de ter direito sobre o próprio corpo, tornando-se, pelo Estado, escravos legais.

Por este principio que se realizou a grande obra da "civilização" portuguesa após a Conferência de Berlim. Foi com este verbo (obrigar), que os indígenas passaram a escravos disfarçados, pois com base no que ficou acordado nessa Conferência e na que lhe seguiu, a ocupação efetiva da África portuguesa foi realizada baseada neste principio. Isto passava por uma enorme modificação na administração das províncias, bem como, no trato com os indígenas, que a partir de 1899, pela legislação portuguesa, adaptada ao discurso internacional, tinham a obrigação moral e legal de trabalhar como forma de melhorar a sua

36 AHU. Liv. 1906-1908, pp. 7-8 Acta da sessão de 02.05.1908 do Conselho de Governo da Província de Moçambique. 
condição material e moral. Tal obrigação, se não cumprida voluntariamente seria imposta pelo Estado. Ou seja, o Estado, com o apoio da lei, obrigava o indígena a trabalhar, não só para si, Estado, como também para particulares. Tudo com objetivo de cumprir a missão civilizacional a si atribuída, como bem expôs o Sr. Antonio Eduardo Villaça, Ministro da Marinha e Ultramar quando apresentou a proposta à Câmara dos Deputados:

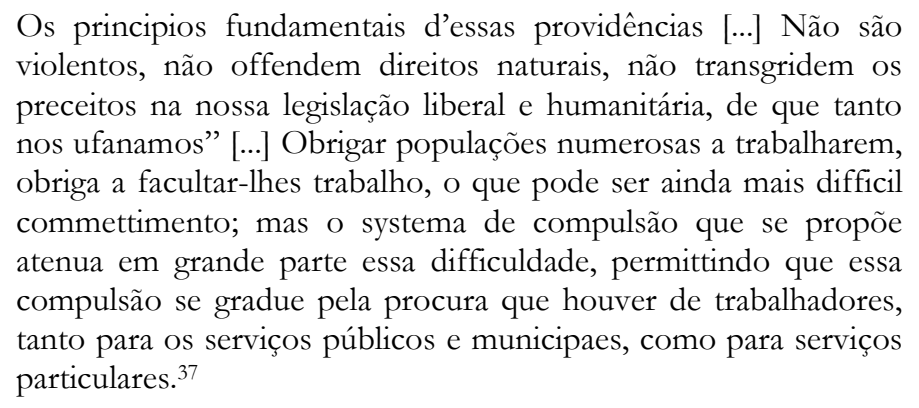

A reunião de todos estes princípios justificou todas as medidas de exclusão tomadas pela administração portuguesa em relação aos indígenas.

\section{BIBLIOGRAFIA}

\section{LITERATURA E OBRAS PERÍODO COLONIAL}

1. AlbuQUerQue, Mouzinho de, Providências Publicadas pelo Comissário Régio na Provincia de Moçambique de 1 de Dezembro de 1896 até 18 de Novembro de 1897, Lisboa, Imprensa Nacional,1898

2. CARVAlHO, Tito de "Revista Ultramarina", Revista Portugueza Colonial e Maritima,Terceiro Anno 1899-1900, 1․ Semestre, no.25, Lisboa, Livraria Ferin, 1900

3. COELHO, Agostinho. Relatório do Governador da Provincia de Moçambique, 1883.

4. COSTA, Eduardo,"Governos Coloniais". Revista Portugueza Colonial e Marítima, Quarto. Anno, 1900-1901 nos. 41 e 42, Lisboa, Livraria Ferin, 1901.

5. _— "Estudo sobre a Administração Civil das nossas Possessões Africanas", Congresso Colonial Nacional, Memória apresentada por Eduardo da Costa, Lisboa, Imprensa Nacional, 1903.

6. _ـ Princípio de Administração Colonial.Antologia Colonial Portuguesa, Vol. I, Lisboa. Agência Geral das Colónias. 1946.

7. ENNES,Antonio Moçambique, Relatório apresentado ao Governo. $4^{\mathrm{a}}$.ed. Facsimilada pela de 1946, (1893) Lisboa. Imprensa Nacional, 1971

8. _.. O Trabalho dos Indígenas e o Crédito Agrícola. Antologia Colonial Portuguesa,Vol. I, Política e Administração. Lisboa, Agência Geral das Colónias, 1946.

9. FEIO,Manuel Moreira "A Colonisacão de Moçambique" I Congresso Colonial Nacional, Vol. 1. Conferências Preliminares e Actas. Lisboa, Sociedade de Geografia 1901.

${ }^{37}$ DCSD no. 31 de 20.03.1899, p.58. 
10. GARRET, Thomaz de Almeida, Administração Colonial, $1^{\circ}$. Vol. Porto, ed. do autor,sd.

11. GIRAULT, M.Arthur Condition dês Indigènes au point de vue de la législation civile et criminelle et de la distribution de la justice, Congrès International de Sociologie Coloniale, Tome Premier, Rapports et Procés - Verbaux des séances, Paris, Arthur Rousseau Editeur, 1901

12. LEROY-BEUALIEU, Paul De la Colonisation chez les Peuples Modernes, Paris, Félix Alcan Éditeu, 6a. ed. Vol. II, 1908.

13. MAGALHÃES, Albano de Legislação Colonial, Seu espírito, Sua formação e seus defeitos. Estudos Coloniais I. Lisboa, 1907

14. OLIVEIRA MARTINS, Joaquim Pedro, de O Brasil e as Colônias Portuguesas Lisboa, Guimarães Editores, 1953

15. PESSOA, J.C. Carvalho A Nossa Legislação Ultramarina - Analyse Crítica. Boletim da Sociedade de Geografia no.16,Lisboa, Imprensa Nacional, 19. Série, 1901

16. SÁ DA BANDEIRA, O Trabalho Rural Africano - A Administração Colonial, Lisboa, Imprensa Nacional, 1873.

17. ULRICH, Ruy Ennes Economia Colonial. Liçoes feitas ao Curso do $4^{\circ}$ ano jurídico do ano de 1909-1910 Vol. I. Coimbra, Imprensa da Universidade, 1910.

18. VILHENA,Ernesto Jardim de Questões Coloniais - Discursos e Artigos, Lisboa, Edição do auctor, 1910.

19. VILLAÇA, Antonio Eduardo, Relatório, Propostas de Lei e Documentos relativo ás Possessões Ultramarinas apresentados na Camara dos Senhores Deputados da Nação Portuguesa em sessão de 20 de março de 1899 pelo Ministro e Secretario D'Estado dos Negócios da Marinha e Ultramar Vol. II, Lisboa, Imprensa Nacional, 1899

\section{OBRAS GERAIS}

1. ARENDT, Hannah As Origens do Totalitarismo. Imperialismo e Expansão do Poder, uma análise dialética. Trad. Roberto Raposo.Editora Documentário, RJ. 1976.

2. CAETANO,Marcelo Do Conselho Ultramarino ao Conselho do Império, Lisboa, Ag. Geral das Colónias, 1943.

3. __ Portugal e o Direito Colonial Internacional, Lisboa, Livraria Moraes, 1948

4. —_Tradiçoes, Princípios e Métodos da Colonização Portuguesa, Lisboa, Agencia Geral Ultramar,1951

5. HENRIQUES, Isabel Castro,Os Pilares da Diferença, Relações Portugal-Africa, Séculos XV-XX, Lisboa, Caleidoscópio ,2004.

6. MIRANDA,Jorge As Constituicões Portuguesas 1822-1826-1838-1911-1933-1976. Lisboa, Livraria Petrony, 1976

7. MINISTÉRIO DAS COLONIAS, Colectânea de Legislação Colonial,Lisboa, Ag. Geral das Colónias, 1936

8. REGO, A. da Silva O Ultramar Português no Século XIX (1834-1910)( Palestras na Emissora Nacional de 16 de Fevereiro a 21 de Setembro de 1965).Lisboa, Agência Geral do Ultramar, $2^{a}$ ed. 1969.

9. SILVEIRA, Frederico, "Guiné".Nova História da Expansão Portuguesa, O Império Africano 1825-1890, Vol. X. Jill Dias e Valentim Alexandre, (coord.)Lisboa, Estampa, 2001. 
